Supplement of

\title{
Measurement of alkyl and multifunctional organic nitrates by proton-transfer-reaction mass spectrometry
}

Marius Duncianu et al.

Correspondence to: Benedicte Picquet-Varrault (benedicte.picquet-varrault@lisa.u-pec.fr)

The copyright of individual parts of the supplement might differ from the CC-BY 3.0 licence. 


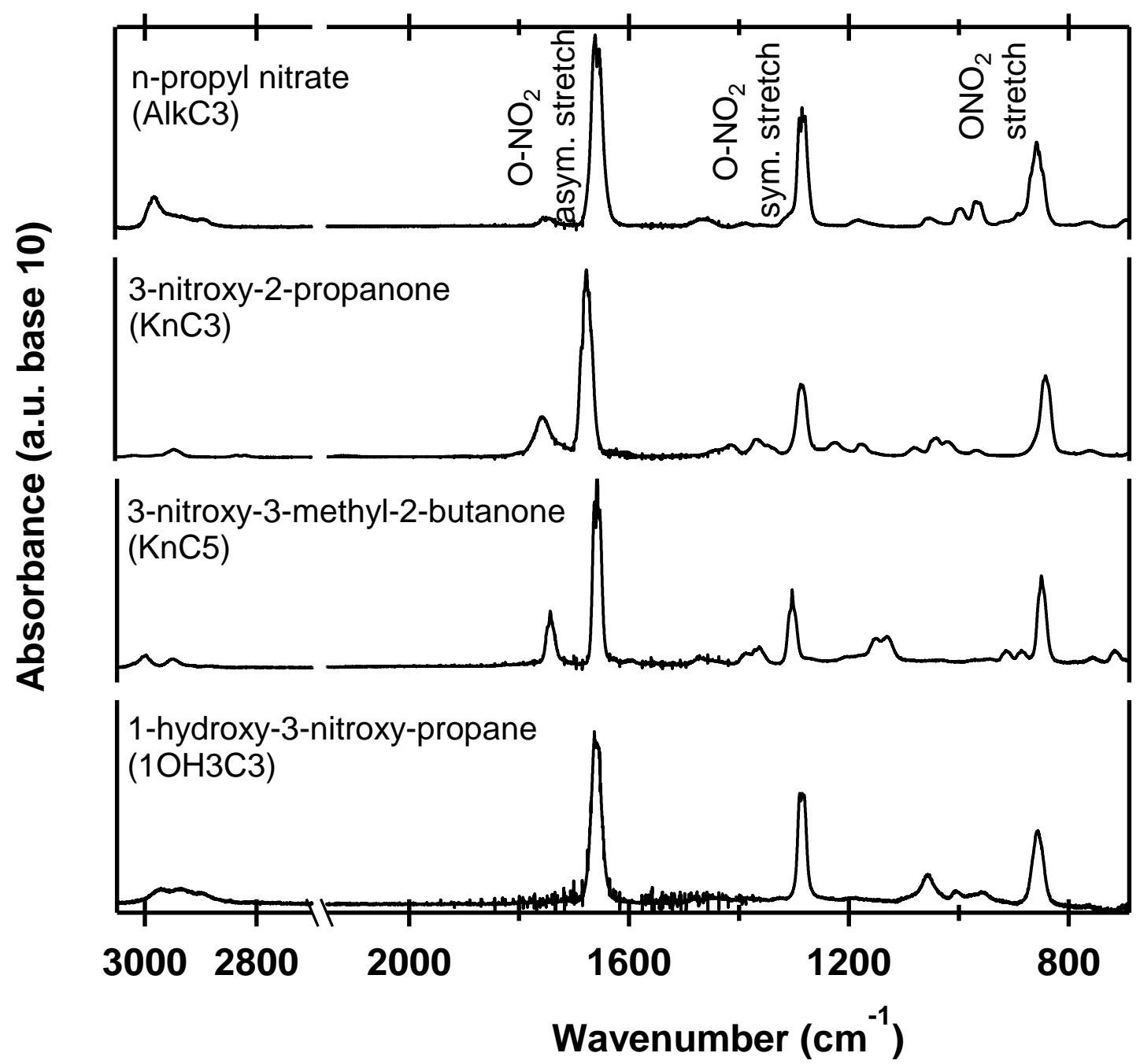

Figure S1. The FTIR gas phase absorbtion spectra of the synthesized organic nitrates (KnC3, $\mathrm{KnC5}, 1 \mathrm{OH} 3 \mathrm{C} 3$ ) compared with a commercially available alkyl nitrate spectra (AlkC3). 


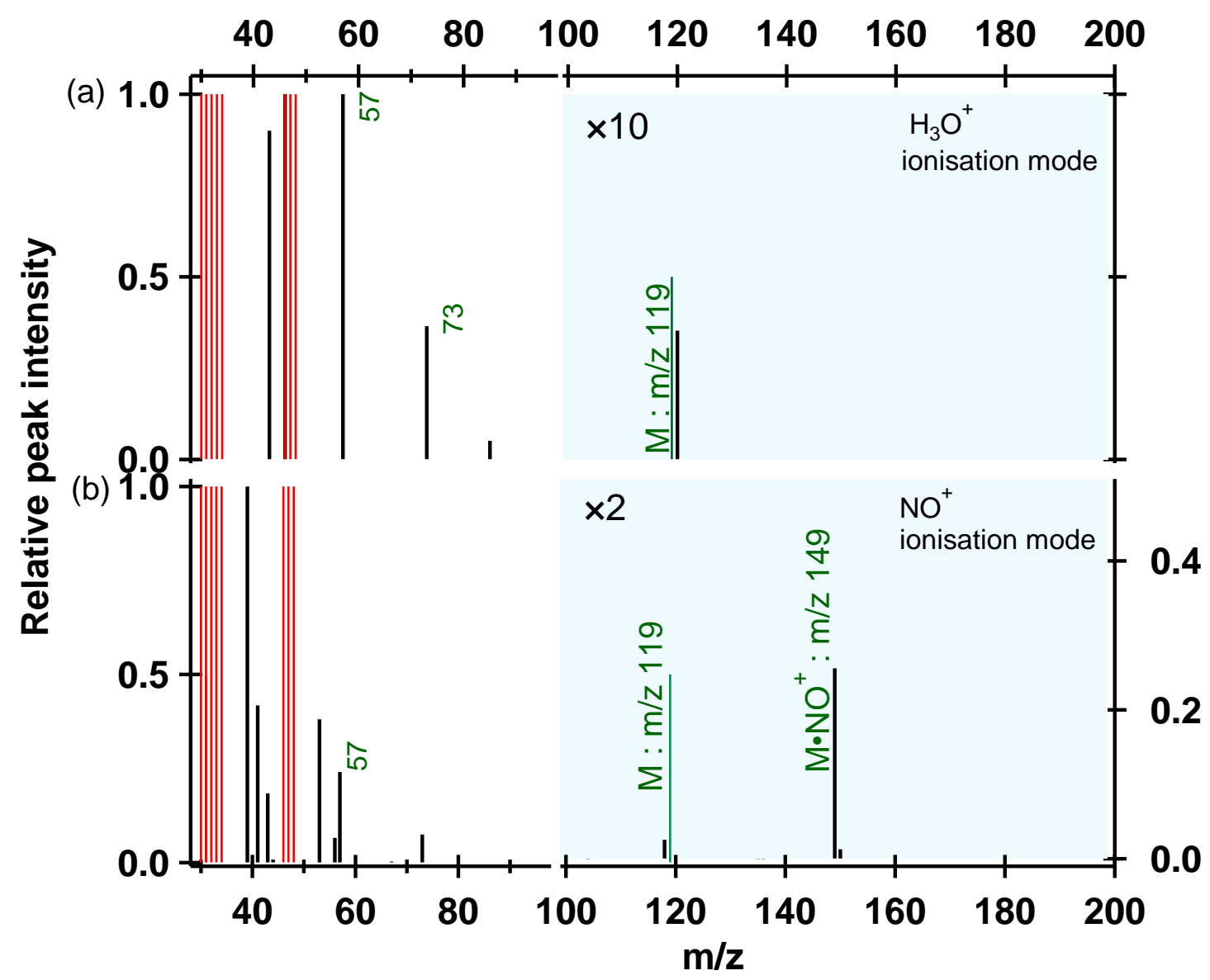

Figure S2. Recorded mass spectrum of protonated AlkiC4 (black bars) for $\mathrm{E} / \mathrm{N}=70 \mathrm{Td}$, corresponding to the highest sensibility for the protonated analyte signal detection $(\mathrm{m} / \mathrm{z} 120)$ in absence of the RF device (a) and in the $\mathrm{NO}^{+}$ionization mode in presence of the $\mathrm{RF}\left(\mathrm{E} / \mathrm{N}^{*}=\right.$ 34 Td) (b). The green thin line represents the expected molecular ion of the analyte. The intense signals depicted by the red thin bars represent the ionizing and matrix analytes at $\mathrm{m} / \mathrm{z}$ $=30\left(\mathrm{NO}^{+}\right)$and $46\left(\mathrm{NO}_{2}{ }^{+}\right)$and their isotopic abundance signals at $\mathrm{m} / \mathrm{z}=31$ and 47,48 respectively. The signals corresponding to the water clusters $\left(\mathrm{H}_{3} \mathrm{O}^{+}\left(\mathrm{H}_{2} \mathrm{O}\right)_{n}\right.$ at $\mathrm{m} / \mathrm{z} 37$ and 55 are systematically erased for simplification. 


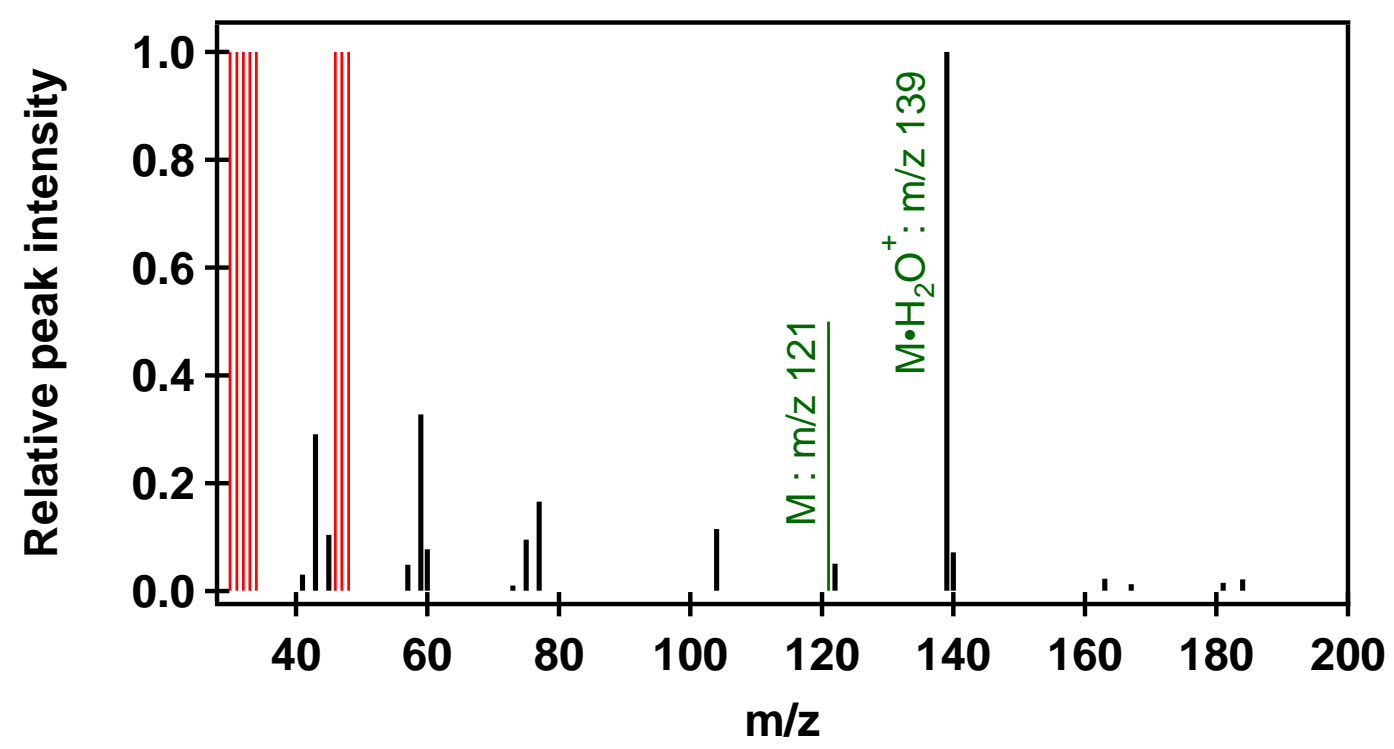

Figure S3. The recorded mass spectrum of 1OH3C3 (black bars) at the lowest extent of fragmentation $\left(\mathrm{E} / \mathrm{N}^{*}=45 \mathrm{Td}\right)$ in the $\mathrm{H}_{3} \mathrm{O}^{+}$ionization mode under the influence of the $\mathrm{RF}$ mode. 


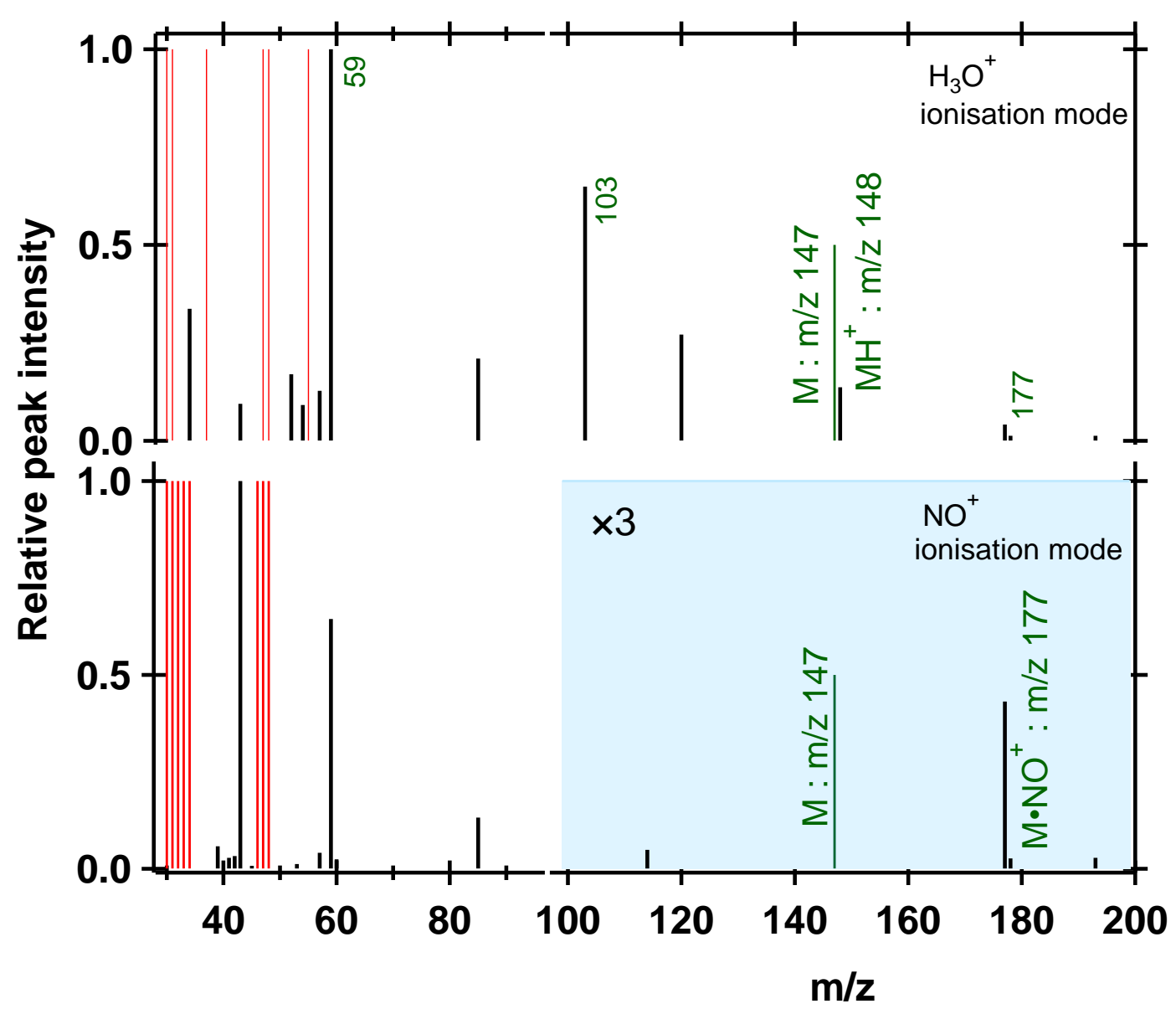

Figure S4. Recorded mass spectrum of protonated KnC5 (black bars) for $\mathrm{E} / \mathrm{N}=75 \mathrm{Td}$, corresponding to the highest sensibility for the protonated analyte signal detection $(\mathrm{m} / \mathrm{z} 148)$ in absence of the RF device (a) and in the $\mathrm{NO}^{+}$ionization mode in presence of the $\mathrm{RF}\left(\mathrm{E} / \mathrm{N}^{*}=\right.$ 36 Td) (b). The green thin line represents the expected molecular ion of the analyte. The intense signals depicted by the red thin bars represent the ionizing and matrix analytes at $\mathrm{m} / \mathrm{z}$ $=30\left(\mathrm{NO}^{+}\right)$and $46\left(\mathrm{NO}_{2}{ }^{+}\right)$and their isotopic abundance signals at $\mathrm{m} / \mathrm{z}=31$ and 47,48 respectively. The signals corresponding to the water clusters $\left(\mathrm{H}_{3} \mathrm{O}^{+}\left(\mathrm{H}_{2} \mathrm{O}\right)_{n}\right.$ at $\mathrm{m} / \mathrm{z} 37$ and 55 are systematically erased for simplification. 


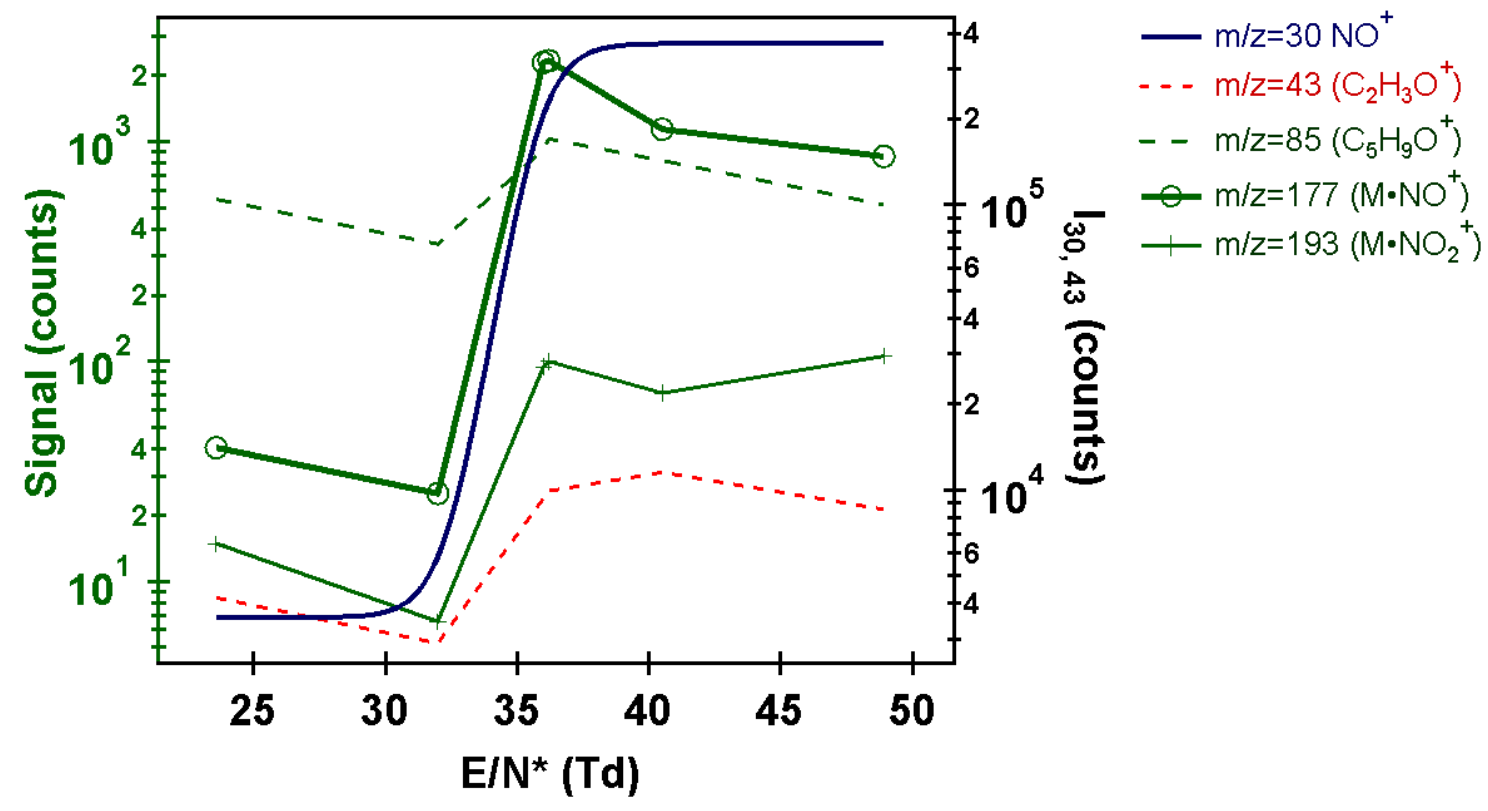

Figure S5. The RF mode behavior of typical $\mathrm{NO}^{+}$ionization signals of keto-nitrates (KnC5) under the $\mathrm{E} / \mathrm{N}$ ratio influence (left axis). Typical distribution of the $\mathrm{NO}^{+}$ions and $\mathrm{C}_{2} \mathrm{H}_{3} \mathrm{O}^{+}$ fragment into the given $\mathrm{E} / \mathrm{N}$ interval (right axis). 


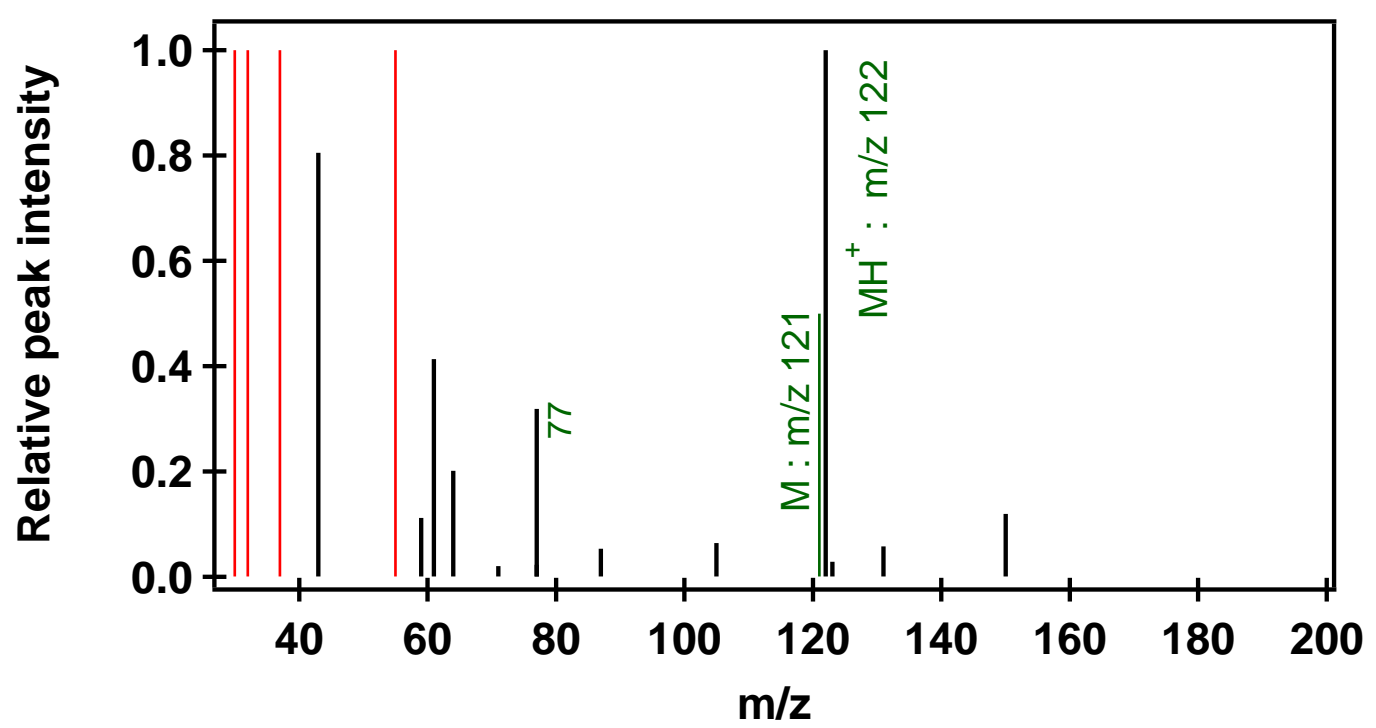

Figure S6. Recorded mass spectrum of protonated PAN (black bars) for $\mathrm{E} / \mathrm{N}=85 \mathrm{Td}$, corresponding to the highest sensibility of the $\mathrm{m} / \mathrm{z} 122$ signal detection. 